\title{
Evaporation Behavior of Al and Sn from Ti-6242 Alloy Melt
}

\author{
Hideo MIZUKAMI, ${ }^{1 * *}$ Tomoyuki KITAURA ${ }^{2)}$ and Yoshihisa SHIRAI ${ }^{1)}$ \\ 1) Steel Research Laboratories, Research \& Development, Nippon Steel Corporation, 2-12-1 Minato, Joetsu, Niigata, $942-8510$ \\ Japan. \\ 2) Naoetsu Area, East Nippon Works, Nippon Steel Corporation, 2-12-1 Minato, Joetsu, Niigata, $942-8510$ Japan.
}

(Received on September 4, 2020; accepted on December 9, 2020)

\begin{abstract}
For multi-component titanium alloy ingots that contain evaporable solute elements, the evaporation behavior of these elements is very important for optimizing the casting conditions. This study examined the evaporation of Al and Sn from molten Ti-6242, an alloy used for aircraft engines, after partial melting in a small electron beam furnace. The amount of Al and Sn evaporation depended on the melting time, and there equilibrium vapor pressure of the elements and activity in the molten alloy. The concentration of $\mathrm{Al}$ changed in proportion to that of $\mathrm{Sn}$ in the molten alloy during evaporation process and the amount of evaporation of Al was twice as Sn. The rate control step of evaporation of Al and Sn were limited by evaporation from the molten alloy surface to the vacuum phase. The liquidus temperature of the alloy melt also changed with the evaporation of $\mathrm{Al}$ and $\mathrm{Sn}$. These findings will help predict the amount of solute evaporation from molten titanium alloys and maintain the surface and internal quality of the ingots.
\end{abstract}

KEY WORDS: evaporation; Al; Sn; molten titanium alloy.

\section{Introduction}

Titanium alloys are used in airplane fuselages and engines, chemical plants, heat exchangers because of their excellent specific strength and corrosion resistance. Since demand for them it is expected to grow in the future, it is important to increase both the production efficiency and quality of titanium alloy ingots. This in turn requires optimization of the casting conditions.

In some cases, titanium alloy ingots are produced with raw materials melted using electron beam heating in a vacuum vessel. This melting process accelerates the evaporation of solute elements from the molten alloys, thus decreasing their concentrations with increasing melting time. Particularly, because multi-component titanium alloys contain many elements having different vapor pressures, it is necessary to quantitatively understand the amount of evaporation for each solute element.

The evaporation behavior of Al from Ti-6Al-4V, which is the most common titanium alloy in general use, has been studied by many researchers. ${ }^{1-10)}$ The amount of Al evaporated from the molten alloy in the electron beam melting furnace was predicted quantitatively using the Langmuir's equation.

These results can clarify the effects melting temperature, melting time, melting rate and the power and pattern of the

\footnotetext{
* Corresponding author: E-mail: mizukami.4m7.hideo@jp.nipponsteel.com
}

electron beam on the amount of $\mathrm{Al}$ evaporation, in order to determine the optimum casting conditions.

However, as far as we know, for multi-component titanium alloy melts containing two or more solute elements with high vapor pressure, there are no reports on their evaporation behavior by considering the mutual interaction of solute elements.

Meanwhile, there is increasing demand for heat-resistant titanium alloys containing a number of solute elements that are prone to evaporation in the melting process. Thus, it is important to understand the evaporation behavior of multiple solute elements in such alloys.

In this study, we examined the evaporation behavior of multi-component alloy Ti-6242 containing Al and Sn with high vapor pressure using a lab-scale electron beam furnace. This alloy is resistant to high temperatures and is used in engine components of airplanes. Moreover, the influence of $\mathrm{Sn}$ on the evaporation behavior of $\mathrm{Al}$ from the molten alloy was also evaluated using the general-purpose thermodynamic software.

\section{Experimental Procedures}

Figure 1 shows a schematic diagram of the experimental apparatus. A cylindrical ingot of Ti-6242 alloy $\left(1.0 \times 10^{-1} \mathrm{~m}\right.$ in diameter and $5.0 \times 10^{-2} \mathrm{~m}$ in height) was set in the water-cooled copper mold in the vacuum vessel. In terms of mass, the ingot contained 


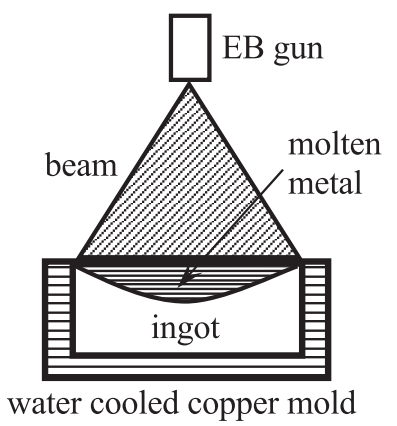

Fig. 1. Experimental apparatus for melting of the surface of Ti-6242 alloy ingot using electron beam. Ingot size: $1 \times$ $10^{-1} \mathrm{~m}$ in diameter and $5 \times 10^{-2} \mathrm{~m}$ in height.

$6.03 \% \mathrm{Al},-1.95 \% \mathrm{Sn},-4.08 \% \mathrm{Zr},-2.10 \% \mathrm{Mo},-0.09 \% \mathrm{Si}$. The top surface of the ingot was irradiated with an electron beam at the maximum power of $15 \mathrm{~kW}$ to maintain a surface temperature of the central region at $2123 \pm 10$ $\mathrm{K}$. The temperature of the periphery of molten region was also $2123 \pm 10 \mathrm{~K}$. By varying the melting time between 120-1 $800 \mathrm{~s}$, the amount of solute evaporation was changed. After the electron beam was turned off, the upper region of the ingot solidified through radiative cooling as well as heat transfer to the water-cooled copper mold.

After the experiment, the ingot was cut longitudinally at the center of the upper surface, and the solidification microstructure in this section was examined. Dendritic structure is formed in the solidified titanium alloy. ${ }^{11)}$ So, the region with observed dendritic microstructure was classified as the remelted region. The microstructure was revealed by etching with 5 vol\% nitric hydrofluoric acid solution.

Mapping analysis of the solute elements in the remelted region was conducted using electron probe micro analysis (EPMA). To evaluate the concentration change in the remelted region, samples were obtained within $2.5 \times 10^{-3}-$ $2.75 \times 10^{-2} \mathrm{~m}$ from the surface of the ingot at $5.0 \times 10^{-3} \mathrm{~m}$ intervals, and the elemental concentrations were measured using inductively coupled plasma (ICP).

\section{Results and Discussion}

\subsection{Estimation for Volume of Molten Region}

Figure 2(a) shows the macrostructure along the longitudinal cross section at the center of the surface when the melting time was $1200 \mathrm{~s}$. The microstructure was revealed by etching with a nitric hydrofluoric acid solution. Two arcshaped boundaries were observed on this cross section. The region above the top boundary corresponds to the solidified region after remelting. The region between the two boundaries is the heat affected zone.

The dendritic microstructure could not be revealed using nitric hydrofluoric acid solution. Therefore, mapping analysis of this cross section was conducted with EPMA.

Figure 2(b) shows the result of mapping analysis for Mo in the square region outlined in Fig. 2(a). A dendritic microstructure was formed on both sides of the remelted region during solidification.

After the electron beam was turned off, dendrites grew from the remelted surface toward the interior of the ingot due to radiative cooling at the top. At the same time, den-
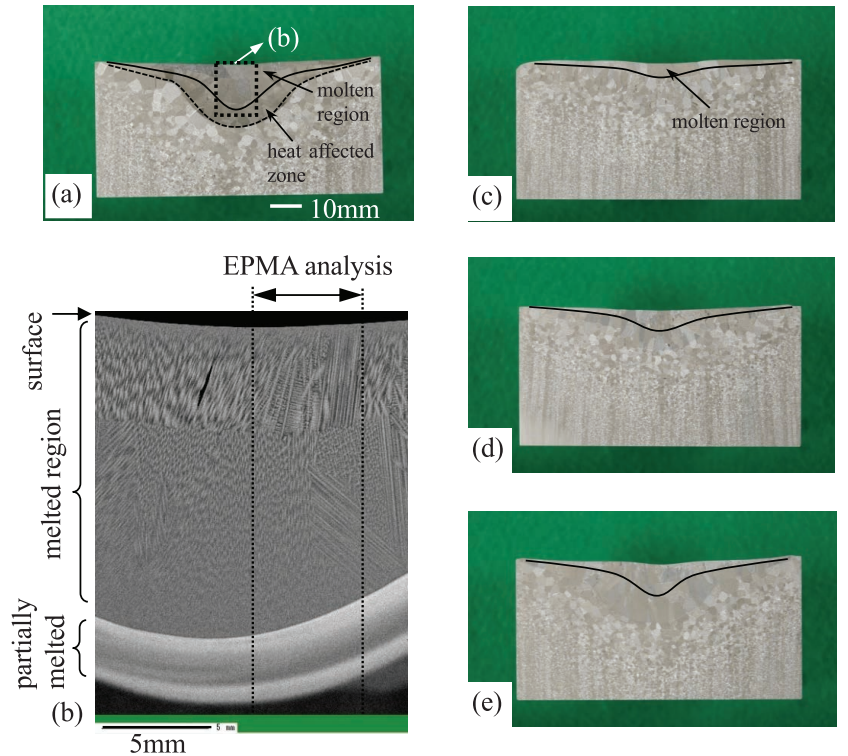

Fig. 2. Solidification microstructures of ingot. (a) longitudinal cross section of ingot, (b) EPMA mapping of Mo. Longitudinal cross section of ingot of which surface region was melted for (c) $120 \mathrm{~s}$, (d) $300 \mathrm{~s}$ and (e) $600 \mathrm{~s}$, respectively. (Online version in color.)

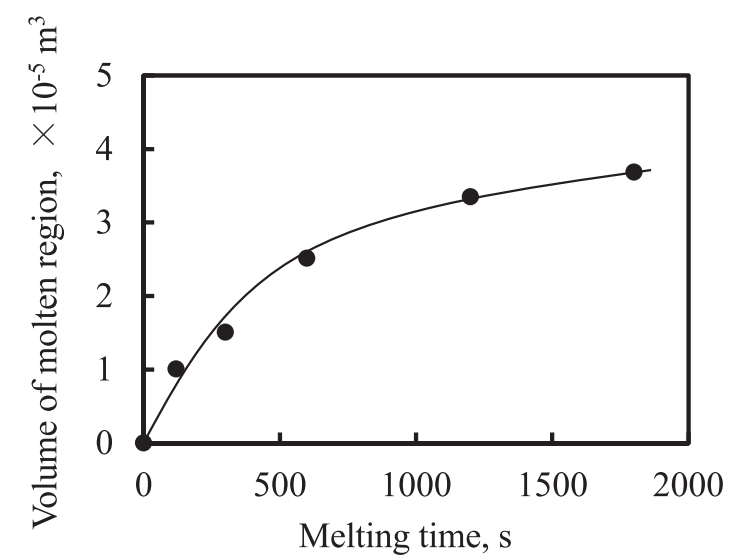

Fig. 3. Change of the volume of molten region in the ingot with melting time.

drites also grew from the bottom of the remalted region toward the top surface due to heat transfer to the water cooled copper mold through the bottom and side of the ingot.

Figures 2(c)-2(e) show the macrostructure along the longitudinal cross section at the center of the surface when the melting time was 120, 300 and 600 s, respectively.

During the electron beam irradiation, the molten region gradually expanded in time from the top surface to the inside of the ingot. The observed microstructure indicates that the shape of the region was axially symmetric; hence, its volume would be evaluated accordingly.

Figure 3 plots the volume of this region vs. the melting time, showing a positive correlation between the two as expected.

\subsection{Change of Solute Concentration in the Melted Region}

The melted region could be visually identified in Fig. 
2(b). To examine the evaporation behavior of solute elements from this region, it is necessary to understand the change of their concentration there.

Drilled chips were obtained at different depth from the top surface, and their elemental concentrations were analyzed.

Figure 4(a) plots concentrations of the solute elements Al and $\mathrm{Sn}$ versus the distance from the top surface, when the melting time was $1200 \mathrm{~s}$. The alloy did not melt at a depth of $1.9-2.75 \times 10^{-2} \mathrm{~m}$, and the composition there matches the initial composition in the ingot. Within the melted region ( depth: $0-1.25 \times 10^{-2} \mathrm{~m}$ ), the concentration of $\mathrm{Al}$ was almost uniform and below the original value. Similarly, the concentration of $\mathrm{Sn}$ also became lower in the melted region.

Figure 4(a) shows the results of EPMA at the melting time of $1200 \mathrm{~s}$ for $\mathrm{Al}$ and $\mathrm{Sn}$, respectively. The region indicated by arrows in Fig. 2(b) was analyzed within $2.0 \times$ $10^{-2} \mathrm{~m}$ from the surface. A partially-remelted region was observed between the melted and non-melted ones, because under irradiation from the electron beam the remelted region increased from the surface to the inside of the ingot and the temperature gradient was generated. The partially-remelted region which corresponded to the solid-liquid coexistent temperature range was formed between those regions. The concentration in this region also changed with the temperature according to the phase diagram.
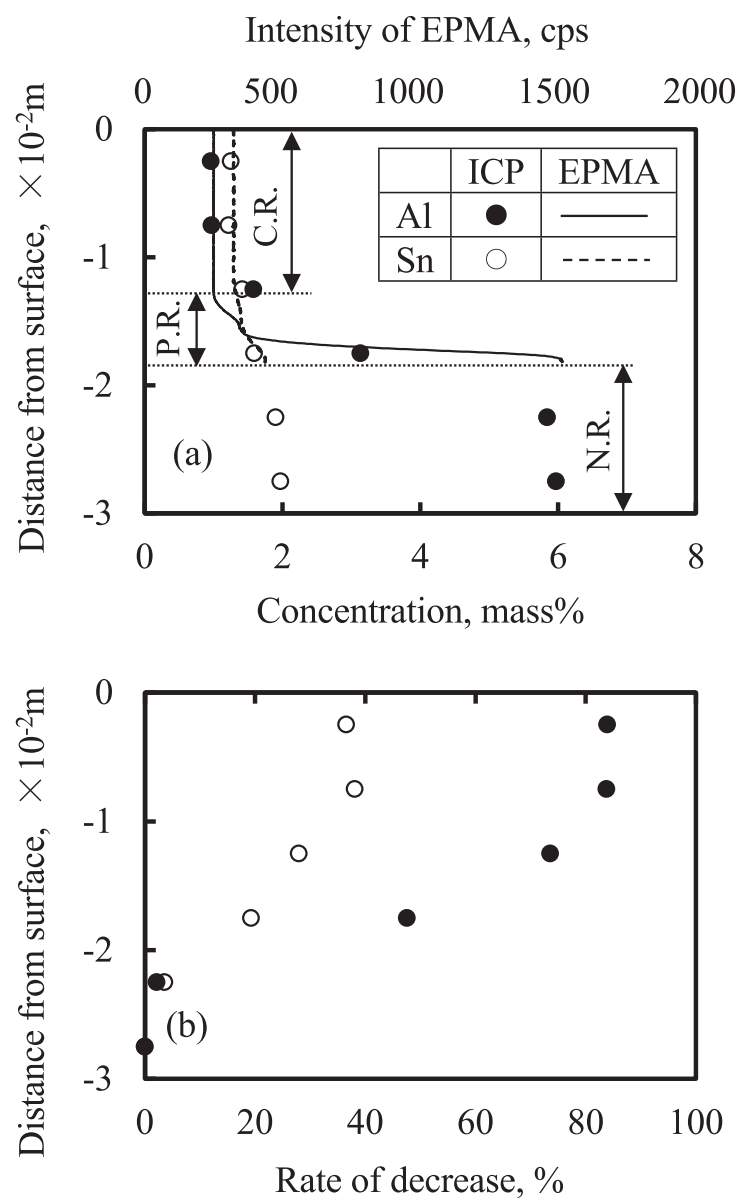

Fig. 4. Relationship between distance from surface of ingot and concentration analized by ICP, intensity of EPMA, rate of decrease when melting time was $1200 \mathrm{~s}$. (a) concentration and intensity and (b) rate of decrease. C.R.: completely remelted region, P.R.: partially remelted region, N.R.: non remelted region.
The EPMA result confirmed that the concentrations of both $\mathrm{Al}$ and $\mathrm{Sn}$ were uniform in the completely melted region.

Figure 4(b) plots the relationship between the distance from the top surface and the decrease rates for concentrations (i.e.: the concentration change divided by initial concentration) after the same melting time. The decrease rate of Al within the melted region was high (approximately 80\%), while that of $\mathrm{Sn}$ was approximately half of that of $\mathrm{Al}(40 \%)$.

From these results, it was confirmed that the two solute elements with high vapor pressure in the multi-component ally melt had different evaporation rates. The amount of solute evaporation from the molten alloy is expected to increase when the melting time becomes longer.

Figure 5(a) shows the relationship between the concentrations of $\mathrm{Al}$ and $\mathrm{Sn}$ at $2.5 \times 10^{-3} \mathrm{~m}$ from the top surface and the melting time. Since their concentrations were almost uniform within the melted region, their values at a depth of $2.5 \times 10^{-3} \mathrm{~m}$ were taken as representative. Indeed, both the concentrations of $\mathrm{Al}$ and $\mathrm{Sn}$ decreased with increasing melting time, confirming enhanced solute evaporation during prolonged melting.

Figure 5(b) further plots the relationship between the decrease rates of $\mathrm{Al}$ and $\mathrm{Sn}$ concentration at a depth of $2.5 \times 10^{-3} \mathrm{~m}$ and the melting time. The decrease rate both grew with the melting time in similar trends. However, the decrease rate of $\mathrm{Sn}$ was only one half that of $\mathrm{Al}$, suggesting that the former is relatively more difficult to evaporate.

Thus, the evaporation rate of solute elements from a molten multi-components alloy depends on both the melting time and the type of element.

Figure 6 shows the relationship between the concentra-
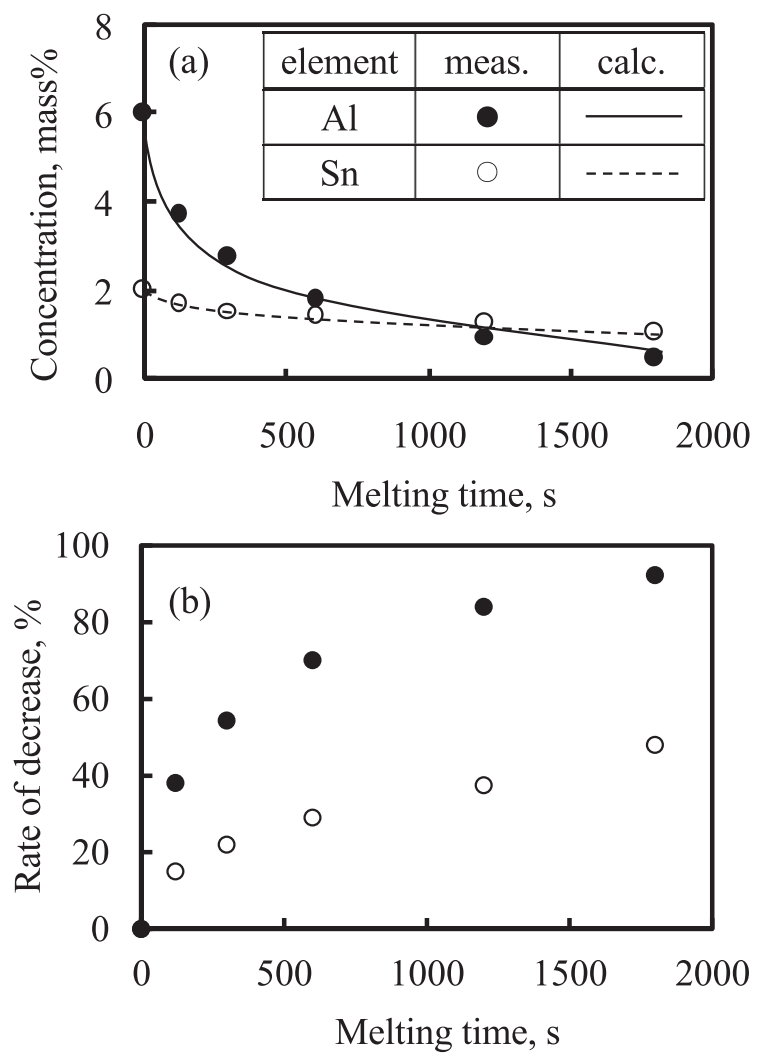

Fig. 5. Relationship between concentration, rate of decrease and time. (a) concentration and (b) rate of decrease. 


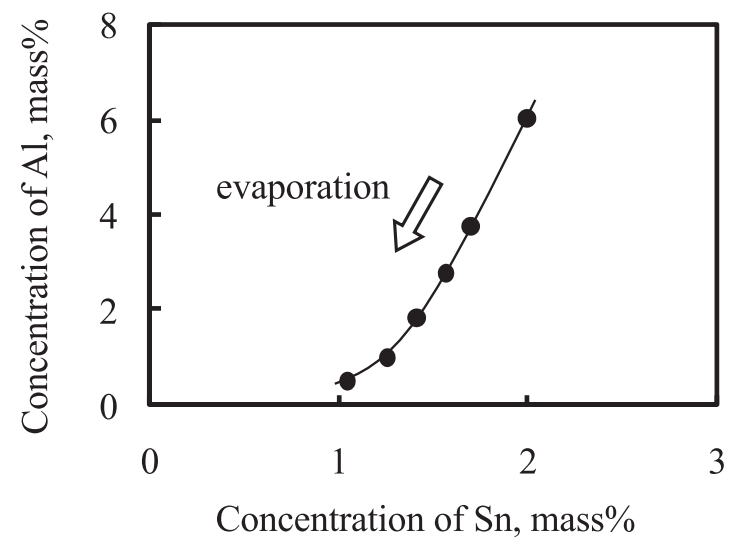

Fig. 6. Relationship between concentration of Al and concentration of Sn under experimental condition in this study.

tion of $\mathrm{Al}$ and $\mathrm{Sn}$. The concentrations of $\mathrm{Al}$ and $\mathrm{Sn}$ were the analytical values at a depth of $2.5 \times 10^{-3} \mathrm{~m}$ from the top surface. The concentrations of $\mathrm{Al}$ and $\mathrm{Sn}$ were in the proportional relation and changed at the same time, because the evaporations of $\mathrm{Al}$ and $\mathrm{Sn}$ occurred simultaneously. Under experimental condition in this study, the concentration of $\mathrm{Al}$ depended on that of $\mathrm{Sn}$, conversely the concentration of $\mathrm{Sn}$ depended on that of $\mathrm{Al}$.

\section{Evaporation from Multi Component Alloy Melt}

The evaporation behavior of solute elements from titanium alloys under vacuum has been studied, ${ }^{2-6,8-10,12)}$ then this study was conducted by the same analysis. However, for multi-component titanium alloy melts containing two solute elements with high vapor pressure, there are no reports on their evaporation behavior by considering the mutual interaction of solute elements. Therefore, in this study, the mutual interaction of $\mathrm{Al}$ and $\mathrm{Sn}$ was considered using the general-purpose thermodynamic software. ${ }^{13)}$

This process is thought to consist of the following three steps, which will be further discussed below.

(1) Mass transfer of solute element inside the molten alloy.

(2) Diffusion of solute element in the boundary layer below the surface of the melt.

(3) Mass transfer of solute element from the melt surface to the vacuum.

\subsection{Mass Transfer of Solute Element in Molten Alloy}

To evaluate the distribution behavior of the solute elements in the molten region, a line analysis was conducted using EPMA. As shown in Fig. 4(a), it was confirmed that the concentrations of $\mathrm{Al}$ and $\mathrm{Sn}$ in the molten region were uniform.

\subsection{Diffusion of Solute Element in Boundary Layer}

In the boundary layer below the surface of the molten alloys, a difference in elemental concentration is generated between the surface and bulk by solute evaporation from the surface. This concentration difference drives the mass transfer of solute elements in the boundary layer, which can be described by the following equations.

$$
J_{i}=k_{\text {diff }, i} S\left(C_{0, i}-C_{S, i}\right)
$$

Where, $\mathrm{k}_{\mathrm{diff}, \mathrm{i}}$ : the mass transfer coefficient $\left(\mathrm{mol} \cdot \mathrm{s}^{-1}\right), \mathrm{S}$ : the surface area $\left(=7.85 \times 10^{-3}, \mathrm{~m}^{2}\right), \mathrm{C}_{0, \mathrm{i}}$ : the concentration $\left(\mathrm{mol} \cdot \mathrm{m}^{-3}\right)$ and $\mathrm{C}_{\mathrm{S}, \mathrm{i}}$ : the surface concentration $\left(\mathrm{mol} \cdot \mathrm{m}^{-3}\right)$.

The parameter $\mathrm{k}_{\mathrm{diff}, \mathrm{i}}$ can be expressed as

$$
k_{\text {diff }, i}=2 \sqrt{\frac{D_{i}}{\pi \theta}} .
$$

Where, $D_{i}$ : the diffusion coefficient of element $i$ in the alloy melt $\left(\mathrm{m}^{2} \cdot \mathrm{s}^{-1}\right), \mathrm{D}_{\mathrm{Al}}=2.1 \times 10^{-8}\left(\mathrm{~m}^{2} \mathrm{~s}^{-1}\right),{ }^{8)} \mathrm{D}_{\mathrm{Sn}}=9.2 \times$ $10^{-9}\left(\mathrm{~m}^{2} \mathrm{~s}^{-1}\right)^{14)}$ and $\theta$ : time (s). In this study, $\theta$ corresponds to the melting time.

\subsection{Mass Transfer of Solute Element to Vacuum}

The evaporation rate of solute element $i$ from the surface of the molten alloy to vacuum can be described using the Langmuir equation.

$$
J_{i}=\frac{\alpha_{i} P_{0, i} \gamma_{i} X_{i}}{\sqrt{2 \pi R T M_{i}}}
$$

Where, $\alpha_{\mathrm{i}}$ : the condensation coefficient of $\mathrm{i}(-), \mathrm{P}_{0, \mathrm{i}}$ : the equilibrium vapor pressure of pure element $i(\mathrm{~Pa}), \gamma_{i}$ : the activity coefficient of element $\mathrm{i}(-), \mathrm{X}_{\mathrm{i}}$ : the mole fraction of element i $\left(\mathrm{kg} \cdot \mathrm{mol}^{-1}\right), \mathrm{M}_{\mathrm{i}}$ : molar weight $\left(\mathrm{kg} \cdot \mathrm{mol}^{-1}\right)$, R: the gas constant $\left(=8.3145 \mathrm{JK}^{-1} \mathrm{~mol}^{-1}\right)$ and $\mathrm{T}$ : the temperature (K). The condensation coefficient was assumed to be $\alpha_{\mathrm{i}}=$ 1.0 same as previous studies..$^{2-4,6,8,9,15)}$

The evaporation rate at the interface between the molten alloy and vacuum is derived using the mass transfer coefficient as follows.

$$
\begin{array}{r}
J_{i}=k_{\text {vap }, i} S C_{S, i} \ldots \ldots \\
k_{\text {vap }, i}=\frac{\alpha_{i} P_{0, i} \gamma_{i}}{\rho_{m} \sqrt{2 \pi R T M_{i}}} \\
\rho_{m}=\sum_{i} \frac{\rho_{i}}{M_{i}} \times f_{i} \ldots .
\end{array}
$$

Where, $\mathrm{k}_{\mathrm{vap}, \mathrm{i}}$ : the mass transfer coefficient of element $\mathrm{i}$ $(-), \rho_{\mathrm{i}}$ : the density of solute element of $\mathrm{i}\left(\mathrm{kg} \cdot \mathrm{m}^{-3}\right), \mathrm{f}_{\mathrm{i}}:$ mole fraction of element $\mathrm{i}(-)$ and $\rho_{\mathrm{m}}$ : the molar density of the molten alloy of Ti-6242 $\left(=1.17 \times 10^{-5} \mathrm{~mol} \cdot \mathrm{m}^{-3}\right)$.

To calculate $\mathrm{J}_{\mathrm{i}}$ from the surface of the molten alloy, it is necessary to evaluate the equilibrium vapor pressure and activity coefficient of element $i$.

The equilibrium vapor pressure of pure element $i$ was described as following equation. ${ }^{16)}$

$$
\log p_{0, i}=-\frac{a_{i}}{T}+b_{i}+c_{i} \log T+d_{i} T \times 10^{-3}
$$

Where, $\mathrm{P}_{0, \mathrm{i}}$ : the equilibrium vapor pressure of pure element $\mathrm{i}(\mathrm{mmHg})$ and $\mathrm{a}_{\mathrm{i}}-\mathrm{d}_{\mathrm{i}}$ : constants as listed in Table $\mathbf{1}$.

There are several methods to calculate the activity. It is possible to calculate the activity based on the phase diagram. Therefore, in this study, the activity of Ti-6242 alloy melt was evaluated using the general-purpose thermodynamic software. ${ }^{13)}$

According to the quasi-regular solution model, ${ }^{17}$ the molar Gibbs free energy in the molten alloy is described as following equation. 
Table 1. Parameter for vapor pressure. ${ }^{16)}$

$$
\begin{aligned}
& \begin{array}{ccccc}
\hline \text { element } & \mathrm{a} & \mathrm{b} & \mathrm{c} & \mathrm{d} \\
\hline \mathrm{Ti} & 23200 & 11.74 & -0.66 & 0
\end{array} \\
& \text { Al } \quad \begin{array}{lllll}
16450 & 12.36 & -1.023 & 0
\end{array} \\
& \begin{array}{lllll}
\text { Sn } & 15500 & 8.23 & 0 & 0
\end{array} \\
& G_{m}=\sum_{i} x_{i} G_{i}+R T \sum_{i} x_{i} \ln \left(x_{i}\right)+\sum_{i} \sum_{j>i} x_{i} x_{j} L_{i j}
\end{aligned}
$$

Here, the interaction parameter is described as following equation.

$$
\begin{aligned}
L_{i j} & =\sum_{k}\left[{ }^{k} L_{i j}\left(x_{i}-x_{j}\right)^{k}\right] \\
{ }^{k} L_{i j} & =a_{k}+b_{k} T+c_{k} T \ln (T)
\end{aligned}
$$

The chemical potential is described as following equation using the partial differential of the Gibbs free energy.

$$
\begin{gathered}
\mu_{i}=\left(\frac{\partial G}{\partial N_{i}}\right) . \\
G=G_{m} \sum_{i} N_{i}
\end{gathered}
$$

By the way, the activity is defined as following equation.

$$
\mu_{i}={ }^{0} G_{i}+R T \ln \left(a_{i}\right)
$$

From the Eqs. (11) and (13), the activity can be evaluated.

Where, $\mathrm{G}_{\mathrm{i}}$ : Gibbs free energy, $\mathrm{G}_{\mathrm{m}}$ : molar Gibbs free energy of molten alloy, $\mathrm{G}_{\mathrm{i}}$ : molar Gibbs free energy of a component i, ${ }^{0} \mathrm{G}_{\mathrm{i}}$ : reference state of molar Gibbs free energy for a pure component $\mathrm{i}, \mathrm{x}_{\mathrm{i}}$ : mole fraction of component $\mathrm{i}$, $\mathrm{R}$ : gas constant, $\mathrm{T}$ : temperature, $\mathrm{L}_{\mathrm{ij}}$ : interaction parameter of component between $\mathrm{i}$ and $\mathrm{j},{ }^{\mathrm{k}} \mathrm{L}_{\mathrm{ij}}$ : parameter, $\mathrm{a}_{\mathrm{k}}-\mathrm{c}_{\mathrm{k}}$ : constant, $\mu_{\mathrm{i}}$ : chemical potential of component $\mathrm{i}, \mathrm{N}_{\mathrm{i}}$ : mole of component $\mathrm{i}, \mathrm{a}_{\mathrm{i}}$ : activity of component $\mathrm{i}$.

Figure 7 shows the relationship between the equilibrium vapor pressure of pure element and temperature. For each element, the equilibrium vapor pressure increases with increasing temperature. However, since the different elements vary in their vapor pressures, their tendencies for evaporation are also different.

The activity of element $i$ in the multi-component alloy melt can be calculated using the general-purpose thermodynamic software. ${ }^{13)}$

Figure 8 shows the relationship between the activity of $\mathrm{Al}, \mathrm{Sn}$ and $\mathrm{Ti}$ and the concentration of Sn at $2123 \mathrm{~K}$. The activities were calculated using the general-purpose thermodynamic software. The activities of Al, Sn and Ti depended on the concentration of $\mathrm{Sn}$. When the concentration of $\mathrm{Sn}$ decreased, the activities of $\mathrm{Al}$ and $\mathrm{Sn}$ decreased.

Figure 9 shows the relationship between the activity of $\mathrm{Al}$ and the activity of Sn under experimental condition in this study. When the activity of Al was decided, the activity of Sn was decided. On the other hand, when the activity of Sn was decided, the activity of Al was decided. The activity of $\mathrm{Al}$ decreased with decreasing the activity of $\mathrm{Sn}$.

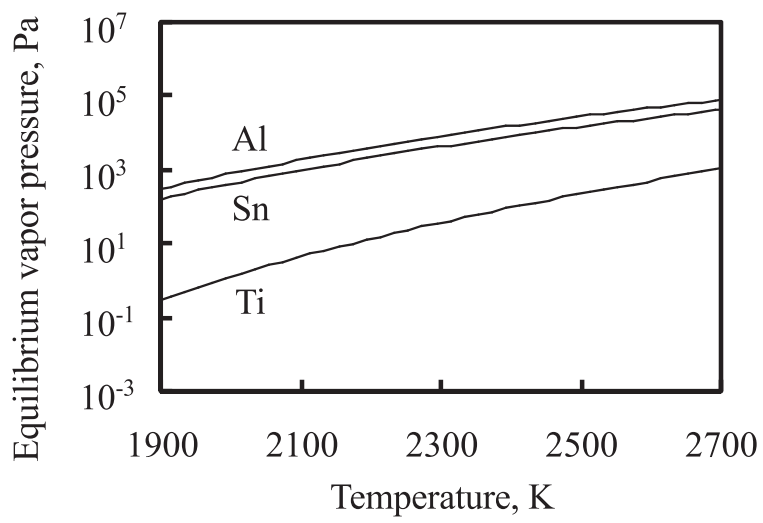

Fig. 7. Relationship between equilibrium vapor pressure of pure element and temperature.

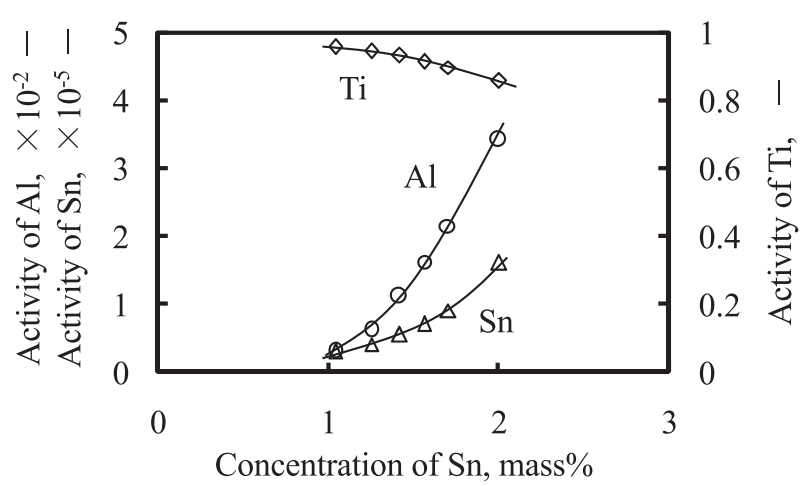

Fig. 8. Relationship between Activity of Al, Sn and Ti and concentration of Sn at $2123 \mathrm{~K}$.

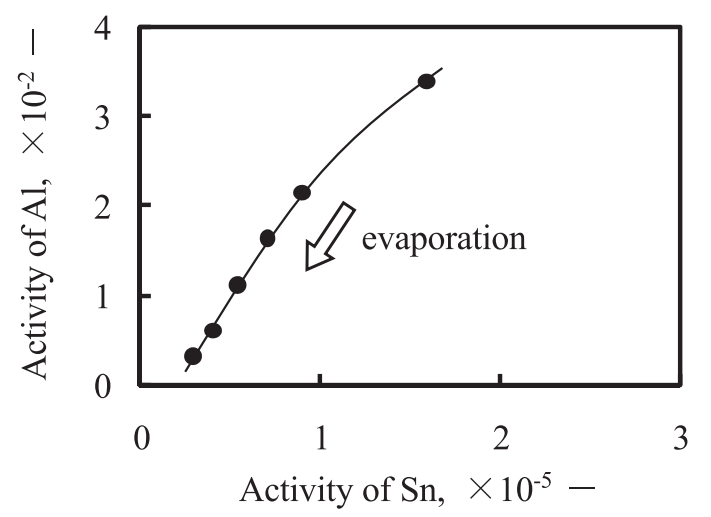

Fig. 9. Relationship between activity of Al and Activity of $\mathrm{Sn}$ at $2123 \mathrm{~K}$ under experimental condition in this study.

\subsection{Overall Evaporation Rate}

The processes discussed in Section 4.1-4.3 sequential. Hence, the overall evaporation rate can be described using the following equations.

$$
J_{i}=k_{\text {all }, i} S C_{0, i}
$$

$$
k_{\text {all }, i}=\left(\frac{1}{k_{\text {diff } . i}}+\frac{1}{k_{\text {vap }, i}}\right)^{-1}
$$

Because the value of the Eq. (2) diverged at time $0 \mathrm{~s}$, then the initial concentration of $\mathrm{Al}$ and $\mathrm{Sn}$ was given to the concentrations at time $0.1 \mathrm{~s}$. Conducting the sequential computation using the Eqs. (1)-(15) with a time step of $0.1 \mathrm{~s}$, it 
was possible to predict the solute elements evaporated from the alloy melt. This amount of the alloy melt was used to determine the mass of solute element based on the changing volume of the melted region (Fig. 3). The activity of Al and Sn was calculated using the general-purpose thermodynamic software. The overall mass transfer coefficient $\mathrm{k}_{\text {all,i }}$ of solute element $i$ is limited by either the mass transfer coefficient $\mathrm{k}_{\mathrm{diff}, \mathrm{i}}$ (in the boundary layer below the surface of the molten alloy) or the mass transfer coefficient $\mathrm{k}_{\text {vap. }}$ (at the interface between the molten alloy and vacuum).

Figure 10(a) shows the relationship between the mass transfer coefficient of $\mathrm{Al}$ and melting time. The $\mathrm{k}_{\mathrm{all}, \mathrm{Al}}$ is limited by the $\mathrm{k}_{\mathrm{vap}, \mathrm{Al}}$, since the latter was smaller than the $\mathrm{k}_{\text {diff.Al }}$. The $\mathrm{k}_{\text {diff,Al }}$ and the $\mathrm{k}_{\text {vap.Al }}$ decreased with increasing melting time.

Figure 10(b) shows the corresponding relationship for $\mathrm{Sn}$. In this case, the $\mathrm{k}_{\mathrm{all}, \mathrm{Sn}}$ was limited by the $\mathrm{k}_{\mathrm{vap} . \mathrm{Sn} \text {, which was }}$ lower than the $\mathrm{k}_{\mathrm{diff}, \mathrm{Sn}}$. With increasing melting time, the $\mathrm{k}_{\mathrm{vap.Sn}}$ and the $\mathrm{k}_{\mathrm{diff}, \mathrm{Sn}}$ the decreased slightly.

As explained above, the mass transfer of both $\mathrm{Al}$ and $\mathrm{Sn}$ was limited by its evaporation at the interface between the molten alloy and vacuum.

The predicted concentrations of $\mathrm{Al}$ and $\mathrm{Sn}$ are plotted as curves in Fig. 5(a). Considering their good agreement with the measured values (scattered dots), we concluded that the model proposed in this study could accurately predict the amount of evaporable elements that escapes from alloy melts.

\subsection{Effect of $\mathrm{Sn}$ on the Evaporation Behavior of $\mathrm{Al}$}

The evaporation behavior for multi-component titanium alloy melts containing two solute elements of $\mathrm{Al}$ and $\mathrm{Sn}$ with high vapor pressure was considered.

Moreover, the evaporation behavior for multi-component titanium alloy melts of Ti- $64^{11)}$ containing one solute ele-
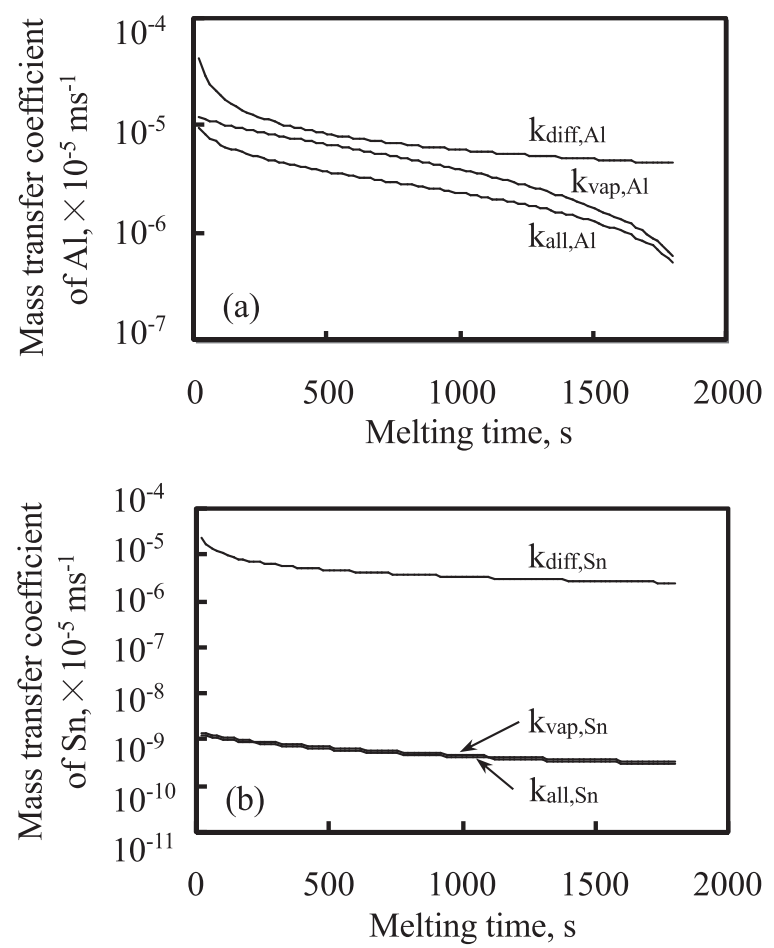

Fig. 10. Relationship between mass transfer coefficient and melting time of (a) Al and (b) Sn at $2123 \mathrm{~K}$. ment of Al with high vapor pressure was examined.

Figure 11 shows the relationship between the concentration of $\mathrm{Al}$ and the melting time. However, the temperature of the molten alloy of Ti-64 was $2273 \mathrm{~K}$, then that temperature was higher than $2123 \mathrm{~K}$ in this study. The concentration of $\mathrm{Al}$ in the molten alloy of Ti-64 decreased with increasing the melting time. Though the temperature of Ti-64 was higher than that of Ti-6242, the amount of evaporation of Al from Ti-64 was lower than that of Ti-6242. It is thought that the concentration of $\mathrm{Al}$ in the molten alloy decreases with increasing the temperature because the amount of the evaporation of $\mathrm{Al}$ from the molten alloy increases with increasing the temperature. Nevertheless, the concentration of $\mathrm{Al}$ in Ti-6242 was lower than that of $\mathrm{Al}$ in Ti-64. As shown in Fig. 8, the activity of Al increases when $\mathrm{Sn}$ is contained in the alloy melt.

It was confirmed that the evaporation of $\mathrm{Al}$ from Ti-6242 alloy melt containing two solute elements of $\mathrm{Al}$ and $\mathrm{Sn}$ with high vapor pressure was accelerated by containing of Sn.

\subsection{Change of Liquidus Temperature by Evaporation}

By the way, the liquidus temperature of the alloy melt would change when the solute elements evaporate from its.

Figure 12 shows the relationship between the liquidus temperature and the melting time. The liquidus temperature was calculated using the general-purpose thermodynamic software ${ }^{13)}$ varied with the measured concentration shown

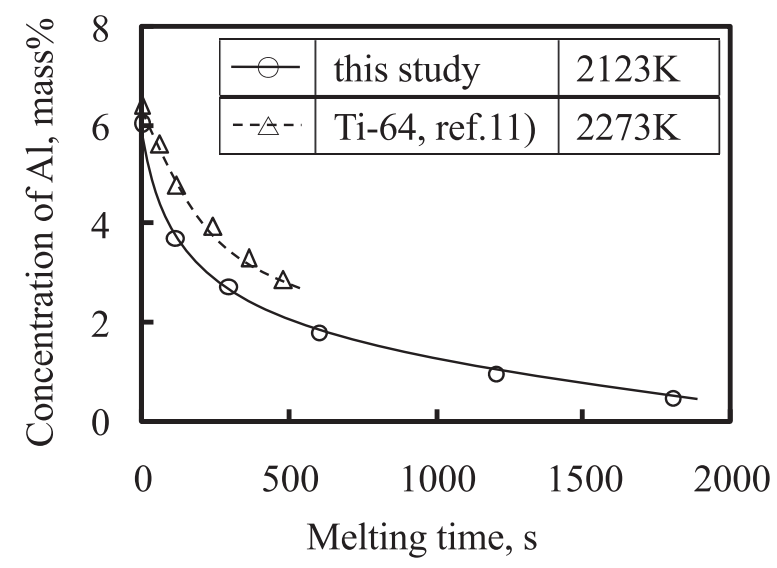

Fig. 11. Relationship between concentration of $\mathrm{Al}$ of Ti-6242 alloy at $2123 \mathrm{~K}$ and Ti-64 alloy at $2273 \mathrm{~K}$ and melting time.

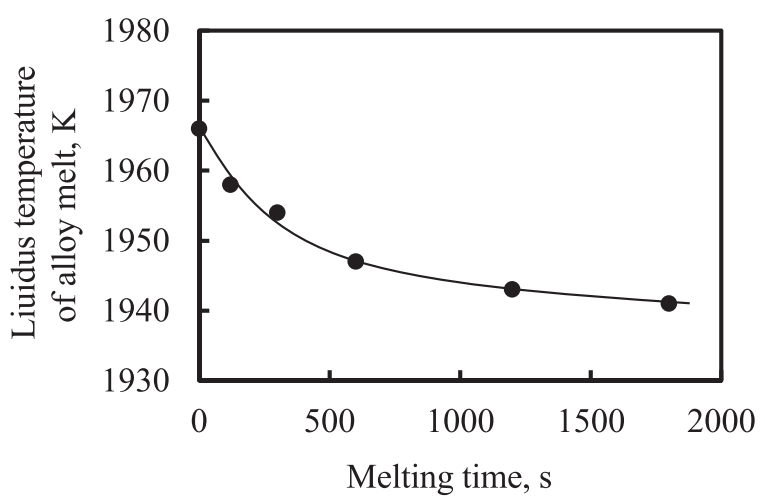

Fig. 12. Change of liquidus temperature of alloy melt with melting time. 
in Fig. 5(a). When the melting time became long, the concentration of $\mathrm{Al}$ and $\mathrm{Sn}$ in the molten alloy decreased, which would reduce the liquidus temperature. The liquidus temperature according to the calculated phase diagram of Ti-6242 ${ }^{13)}$ increases with increasing the concentration of $\mathrm{Al}$ in the range from 0 to $10 \mathrm{mass} \%$.

This change in the liquidus temperature in turn affects the superheat of molten alloy in the continuous casting mold. The superheat influences not only the growth behavior of the initially solidified shell in the mold, but also the length of the final position of solidification front from the meniscus of the ingot.

Therefore, understanding the evaporation behavior of solute elements from the molten alloy is important for controlling not only the composition of the molten alloy, but also the solidification behavior of the ingots and castings.

\subsection{Application of Evaporation Behavior to the Hearth and Mold}

In this study, the experiment was conducted using a labscale electron beam furnace. The top surface of the ingot was irradiated with an electron beam and the surface layer was remelted. It seems that natural convection is generated in the molten alloy and the flow velocity is relatively slow. From the results of a line analysis using EPMA, it was confirmed that the concentration of the solute elements in the molten alloy was uniform. Then, the movement of the elements in the molten alloy did not become a ratedetermining step.

When the molten alloy in the hearth is poured into the mold in the real operation, forced convection is generated in both the hearth and the mold. Therefore, flow velocity in both the hearth and the mold becomes faster than the case of natural convection. It is thought that the movement of the solute elements does not become a rate-determining step.

Then, the evaporation behavior of the solute elements from molten alloy in the hearth and mold was predicted using Eqs. (14) and (15). However, it is necessary to evaluate the profile of the molten pool in the hearth and the mold for predicting the amount of evaporation of the solute elements.

\section{Conclusions}

The evaporation behavior of solute elements from molten titanium alloys is a key factor in optimizing the thermal conditions in both ingots and castings. Particularly, for multi-component titanium alloys containing many elements with disparate vapor pressures, it is necessary to quantitatively evaluate the amount of evaporation for each solute element.

This study examined the evaporation behavior of Ti-6242 multi-component alloy (containing the easily evaporating element of $\mathrm{Al}$ and $\mathrm{Sn}$ ) using a lab-scale electron beam melting furnace. The following results were obtained.

(1) Under experimental condition in this study, the amount of evaporation for $\mathrm{Al}$ and $\mathrm{Sn}$ from molten alloy does not change independently and varies proportionately. The amount of Sn evaporation was only one half of that of Al.

(2) The amount of evaporation for $\mathrm{Al}$ increases when $\mathrm{Sn}$ is contained in the molten alloy. The amount of evaporation for Al from Ti-6242 alloy melt is larger than that of Ti-64 which does not contain Sn.

(3) The rate-determining step in solute evaporation for $\mathrm{Al}$ and $\mathrm{Sn}$ are evaporation from the interface between alloy melt and vacuum.

\section{REFERENCES}

1) H. Nakamura and A. Mitchell: ISIJ Int., 32 (1992), 583.

2) T. Isawa, H. Nakamura and K. Murakami: ISIJ Int, 32 (1992), 607.

3) S. Watakabe, K. Suzuki and K. Nishikawa: ISIJ Int., 32 (1992), 625.

4) A. Powell, J. van den Avyle, B. Damkroger, J. Szekely and U. Pal: Metall. Mater. Trans. B, 28 (1997), 1227.

5) J. P. Bellot, E. Hess and D. Ablitzer: Metall. Mater. Trans. B, 31 (2000), 845.

6) S. V. Akhonin, N. P. Trigub, V. N. Zamkov and S. L. Semiatin: Metall. Mater. Trans. B, 34 (2003), 447.

7) V. G. Ivanchenko, O. M. Ivasishin and S. L. Semiatin: Metall. Mater. Trans. B, 34 (2003), 911.

8) S. L. Semiatin, V. G. Ivanchenko, S. V. Akhonin and O. M. Ivasishin: Metall. Mater. Trans. B, 35 (2004), 235.

9) Y. Zhang, L. Zhou, J. Sun, M. Han and Y. Zhao: Int. J. Mater. Res., 100 (2009), 248.

10) A. Klassen, V. E. Forster and C. Körner: Model. Simul. Mater. Sci. Eng., 25 (2017), 025003.

11) H. Mizukami, Y. Shirai, A. Kawakami and A. Mitchell: ISIJ Int., 60 (2020), No. 11, 2455.

12) G. Geiger and D. Poirier: Transport Phenomena in Metallurgy, Addison-Wesley, Reading, MA, (1980), 560.

13) B. Jansson, M. Schalin, M. Selleby and B. Sundman: Computer Software in Chemical and Extractive Metallurgy, ed. by C. W. Bale and G. A. Irons, The MetSoc of CIM, Westmount, QC, (1993), 57.

14) P. G. Sanders, M. O. Thompson, T. J. Renk and M. J. Aziz: Metall. Mater. Trans. A, 32 (2001), 2969.

15) S. Itoh and Y. Inoue: Mater. Trans., 52 (2011), 704

16) E. A. Brandes and G. B. Brook: Smithells Metals Reference Book, Butterworth-Heinemann, Oxford, UK, (1992), 8.

17) H. L. Lukas, S. G. Fries and B. Sundman: Computational Thermodynamics, Cambridge University Press, Cambridge, UK, (2007), 79. 